\title{
Population Issues and Social Indicators of Well-Being
}

\author{
Frank M. Andrews \\ The University of Michigan
}

Relating demographers' measures of various population characteristics (size, growth/decline, density, age/sex structures, migration, et cetera) to measures of well-being recently developed within the social indicators movement promises to provide new knowledge about the linkage of population and well-being that can enhance decision making about important population issues.

A conceptual schema is presented that suggests specific relationships to examine at various levels of aggregation, that helps to classify research already done in this area, and that helps to identify "holes" in the knowledge base.

Some special methodological features of research in this area suggest considerable time and care will be required to produce dependable new knowledge. These include: (a) the inherent multilevel nature of the relationships (involving properties of individuals and collectivities); (b) the slow rate at which population characteristics change; (c) the absence of much good well-being data from the past; and (d) the limited nature of the collectivities for which population data are available.

\section{INTRODUCTION}

One of the most basic ideas that has motivated demographers is the hypothesis that the well-being of members of a population is somehow related to the demographic characteristics of that population. The population parameters that have been considered are many and include population size, density, age-sex structure,

This article is a revised version of a paper presented to the 1981 Annual Meeting of the Population Association of America. Gillian Foo, Anne Lee, Alison Mclntosh, Willard Rodgers, and Arland Thornton made helpful commments on earlier versions of this paper. Frank M. Andrews is affiliated with the Center for Population Planning and the Institute for Social Research at The Univeristy of Michigan, Ann Arbor, MI 48109. Requests for reprints should be directed to Dr. Andrews. 
and geographic distribution, as well as changes in these parameters-including growth or decline in size, increase or decrease in density, and migration phenomena. Furthermore, the presumed relationship between demographic parameters and wellbeing has been viewed from two causal perspectives: Some investigators have suggested that changes in population characteristics produce changes in well-being; others have suggested that changes in well-being produce changes in population characteristics.

Although the basic hypothesis of the existence of a relationship between well-being and population characteristics lies back of much demographic work, and occasionally comes to the fore, this relationship has not yet been extensively explored. What the field of demography has accomplished in its approximately onehalf a century of existence is the development of good methods for measuring a variety of important population characteristics and the assembling of descriptive time-series data for a substantial number of populations. However, in order to examine relationships between population characteristics and well-being, good data about well-being are also needed, and, until recently, broadranging information about well-being has been scant.

It is the thesis of this paper that the social indicators movement, now about fifteen years old, offers methodological experience in the measurement of well-being and an increasing amount of descriptive data, and that an interdisciplinary linkage of the demographers' insights about the measurement of population characteristics and the social indicator researchers' insights about the measurement of well-being offer an exciting new opportunity for exploring the relationships between population change, other basic demographic parameters, and well-being.

This article has several purposes: (a) to call attention to the existence of the new field of social indicators and the potential it holds for generating knowledge relevant to population issues; (b) to describe some of the key conceptual landmarks of the social indicators field; (c) to suggest ways in which these conceptual features can be exploited to produce knowledge relevant to population topics; and (d) to note research strategies and approaches that seem particularly promising. These are the respective topics of the following sections of this report. They are followed by a brief summary of the major points. 


\title{
2. SOCIAL INDICATORS AND THEIR RELEVANCE TO POPULATION ISSUES
}

\author{
The Nature of Social Indicators
}

What is a "social indicator"? As one might expect for a field still in the early stages of development, there is not one universally accepted definition. Several descriptions taken from the social indicator literature, however, will indicate the general boundaries of what is being discussed:

A social indicator ... may be defined to be a statistic of direct normative interest which facilitates concise, comprehensive and balanced judgments about the condition of major aspects of a society. It is in all cases a direct measure of welfare and is subject to the interpretation that, if it changes in the "right" direction, while other things remain equal, things have gotten better or people are "better off." (U.S. Department of Health, Education and Welfare, 1969.)

A social indicator... is defined as a direct and valid statistical measure which monitors levels and changes over time in a fundamental social concern. (OECD, 1976.)

Social indicators are time-series that allow comparisons over an extended period which permit one to grasp long-term trends as well as unusually sharp fluctuation rates. ... (Sheldon \& Freeman, 1970.)

Social indicators are quantitative measures of social conditions designed to guide choices at several levels of decision making. (Sawhill, 1969.)

Social indicators refer to social statistics that (1) are components in a social system model ... (2) can be collected and analyzed at various times and accumulated into a time-series, and (3) can be aggregated or disaggregated to levels appropriate to the specifications of the model. (Land, 1971.)

These definitions are not all identical. In fact, whether a social indicator must be a direct measure of welfare (as in the HEW definition) and whether a social indicator must be a component in a social system model (as in Land's definition) have been topics of dispute.

For the purposes of this article, we can resolve the first dispute by restricting our attention to social indicators of wellbeing and by granting that there may be other types of social in- 
dicators that we shall not consider here. By "well-being" we refer to the general notion of how well off people are. As later examples and the discussion in sections 3 and 4 of this paper will make clear, well-being is a multidimensional concept that comprehends many criteria of life quality and many life domains.

As for the second issue, we shall not require that an indicator be part of a formal social system model, but will concur with the widespread view that for a statistic to qualify as a social indicator, it must provide information that informed users believe is of broad social significance.

It may be helpful to provide some examples of social statistics that meet our definition of well-being indicators and of other social statistics that do not. In the field of health, it can be argued that information about people's abilities to perform certain demanding tasks - e.g., reading newspaper print, walking up stairs, running 100 meters - and people's own assessments of their health or physical condition, and aggregated data on life expectancy or infant mortality rates all qualify as well-being indicators. Differences in such statistics between social groups or at different times carry strong implications about who is better off. On the other hand, data about the availability of hospital beds, or patient visits to doctors, or money spent on prescriptions, while surely useful for many purposes, would not qualify as well-being indicators, because it would not be clear whether an increase in such measures indicated an improvement or deterioration of health levels.

Using such well-being indicators, the social indicators movement has undertaken to measure and explore the whole wide domain of well-being more broadly and comprehensively than it has been investigated before.

\section{The Relevance of Well-being Indicators for Population Issues}

What is the relevance of social indicators of well-being for population issues? The answer is short but profound: It is widely believed that there is a strong and direct linkage between levels of well-being and characteristics of populations. Changes in various population parameters are believed to affect levels of well-being, and, conversely, changes in levels of well-being are believed to affect various aspects of population.

For example, in many parts of the world, high rates of population growth are a great concern, because as there are more and more people to feed and house and clothe and educate, the 
available resources for meeting these needs are becoming increasingly thin, and well-being levels are declining or are expected to do so in the near future. In other parts of the world, however, the population is declining, or felt to be not growing fast enough, and here also there are concerns about well-being-that there won't be enough people to sustain the society, to defend it against intrusions, or to support its dependent members.

Population issues, however, are not limited only to questions of size or changes in size, as in the preceding examples. Issues of density and/or crowding also receive attention. How do different levels of density or changes in density levels affext people's quality of life? Other topics traditionally addressed by population researchers - such as the age/sex structure of a population or the geographic distribution and migrations of a population-also motivate people's interest and concern because of presumed links to quality of life.

Although the potential relevance of a wide range of population characteristics to levels of well-being is taken by many people to be "obvious," there is surprisingly little research actually exploring the linkages. Demographers have developed a sophisticated discipline around concepts involving rates of fertility, mortality, migration, marriage, divorce, dependency, and the like, but have done relatively little to link the data they are developing to information about well-being. Social epidemiologists have explored how one aspect of well-being, emotional and physical health outcomes, relates to certain population trends, but the range of well-being phenomena examined has been very limited.

The need and potential for investigating a wide range of linkages between population characteristics and well-being is becoming more widely recognized. In a recent article, the director of the Population Division at the United Nations, Leon Tabah, has written:

A profound economic and social crisis ... has revealed that the problems of population are henceforth inseparable from such other problems as those of the environment ...; of the rational use of resources; of changing lifestyles; and ... of disparities in income between and within countries. Research into the interrelationships between population, resources, the environment, and development strategies has come to be recognized as a new field of study, essential, but scarcely explored, in which it is less a question of assembling facts in each area than of studying the relations between them. (Tabah, 1980, p. 356.) 
By exploiting the potential of social indicators, it seems that several different kinds of new knowledge relevant to population issues can be produced. Basic knowledge about how well-being levels vary under different conditions of population size, density, age/sex structures, urbanization, et cetera-in the presence of various other social and structural conditions - seems a likely outcome. In due course, such basic knowledge could be expected to contribute to a broad range of policy choices.

Even in the short run, however, information from social indicators of well-being could help to enlighten discussion and decision making regarding a number of population topics that are currently being debated in the United States and elsewhere. For example: What is the actual impact on the well-being of teenagers of providing contraceptive services without their parents' knowledge or consent? And what is the impact of such a policy on the parents' well-being? How does the introduction of a sex education program in public schools relate to students' levels of well-being one year, or five years, or ten years later? How do wellbeing levels of children born to unmarried mothers compare with those of children born to married couples? And how do these wellbeing levels change over the first twenty years of the children's lives? How do well-being levels of mothers, fathers, and children compare between areas where legal abortion is readily available and areas where it is not? What impact does the establishment of a family planning clinic in a remote area of a developing country have on the levels of well-being of the inhabitants of that area? Does it make a difference in measurable well-being if a family's size is close to the parents' notion of ideal size?

\section{SOME KEY CONCEPTS AND PERSPECTIVES IN THE FIELD OF SOCIAL INDICATORS}

\section{The Social Indicators Movement}

The nature and bases of human well-being have occupied the attention of philosophers, politicians, and religious thinkers for millennia. In some senses, the modern social indicators movement can be seen as a new approach-using empirical social science concepts and methods - to a very old and important concern.

The modern social indicators movement began in the mid1960 s and has been in vigorous worldwide development for the 
past fifteen years. It had its origin in the realization that traditional economic statistics do not provide the broad-based information needed for monitoring social change, evaluating social programs, guiding policy development, and-in general-assessing quality of life or levels of well-being. This is not the place to present a history of the social indicators movement, and others have assembled annotated bibliographies of some of the more important literature (Gilmartin, Rossi, Lutomski, \& Reed, 1979), but suffice it to say that significant efforts have been devoted by social scientists, statisticians, government administrators, and others to laying the conceptual and operational foundations on which more broadly based social information systems can be built. These activities have occurred in a number of important universities and research institutes around the world, in selected governmental units at virtually all levels, including international organizations - for example, the World Health Organization, the United Nations Educational, Scientific, and Cultural Organization, and the Organization for Economic Cooperation and Development - and in governments of individual countries, states, provinces, counties, and cities. At the national level, many of the more developed countries have published some kind of social indicators report within the past few years, and so also have some of the developing countries. The social indicators movement even has its own international professional journal, Social Indicators Research.

Out of this fifteen-year history of the social indicators movement, several conceptual and methodological perspectives have emerged that constitute important "landmarks" of this new domain and that provide basic features around which subsequent developments are likely to occur. We discuss some of the major ones in the following subsections.

\section{Social Indicators of Well-being and Quality of Life}

The concept "quality of life" has entered into popular use and is frequently linked with social indicators. The linkage is appropriate, for some kinds of social indicators, namely, social indicators of well-being, measure some of the important aspects of life quality. However, it is helpful to note that "quality of life" is a very broad concept and includes matters ranging far beyond the topic of well-being. For example, Hofstede (1980) found that people in different cultures show systematic differences in their preferences for equality, avoidance of uncertainty, collective 
responsibilities, and assertiveness. Such differences would surely lead to differences in the quality of life, but may have little to do with levels of well-being. When people speak or write about "life quality," it is helpful to know whether they refer to the wellfareillfare dimension that is tapped by social indicators of well-being, or to one of the many other dimensions that falls within the life quality concept.

\section{Objective Conditions and Subjective Perceptions}

People exploring and developing the field of social indicators have found it helpful to distinguish between two broad types of indicators: those that tap the "objective" state of affairs and those that indicate "subjective" perceptions and evaluations of those affairs. The reason for monitoring both objective and perceptual indicators is that experience has shown they often give different, but complementary information (Andrews, 1974, 1981; Wasserman \& Chua, 1980; Atkinson, Blishen, \& Murray, 1980). The examples of social indicators cited previously in this paper include both types of indicators: Statistics on life expectancy would be classed as an "objective" indicator, while people's assessments of their own health and physical condition constitute "subjective" indicators. The objective/subjective distinction, however, cannot always be sharply drawn, and some indicators have characteristics of both types - e.g., ratings by experts of housing conditions, air pollution, or the incidence of poverty.

\section{Levels of Specificity}

It has become common practice in the social indicators movement to use indicators at several different levels of specificity. Highly general, or "global," indicators are complemented by an array of more specific indicators. For example, in studies of perceived well-being, a general measure based on people's own evaluations of their "life as a whole" often is accompanied by assessments of more specific life concerns, such as housing, job, family, health, and the like (Andrews \& Withey, 1974, 1976; Campbell, Converse, \& Rodgers, 1976). The same strategy has also been employed with respect to objective indicators, though here questions sometimes arise regarding the appropriateness of the global indicator (Liu, 1970, 1975). (With objective indicators, unlike the perceptual measures, there usually is no independent 
assessment of the global indicator, which instead is merely a weighted composite of the more specific indicators.) Although most current systems of indicators do not represent more than two levels of specificity, there is no inherent reason why the number of levels could not be greater.

Having indicators at several different levels of specificity has numerous advantages. (a) Indicator overload-the presence of more data than even the experts in a field can easily comprehend-is a potential problem, and the summary provided by the more general indicators is one solution. (b) The global indicators are particularly helpful to nonspecialists (a group that includes many policymakers), whose interests often do not extend beyond the most general level. (c) Global indicators, if they are separately measured and not just composites of the more specific indicators, have an important scientific function: They stand as "dependent variables" in their own right, ready to play a role in basic research aimed at understanding what specific factors influence the more general one. (d) The more specific indicators, on the other hand, provide the details that explain why a more global indicator changes over time (or varies from group to group, or from place to place), and they provide the concrete information needed for policy formation and program implementation.

\section{Dynamics of Subjective Evaluation}

There has developed within the social indicators movement a cluster of activities addressed to the issue of how people come to make the subjective evaluations they do about their well-being. Two lines of investigation have been followed.

One has looked at how more global evaluations are formed. They seem to be the result of simple summings of a set of separately measurable more specific evaluations. How a person assesses his or her life as a whole can be remarkably well predicted on the basis of how that person evaluates about a dozen key life concerns (Andrews \& Withey, 1976; Campbell et al., 1976).

The other approach seeks to identify the fundamental underlying components of people's well-being assessments and to understand what influences these components. Most of the perceptual indicators of well-being that have been explored to date seem to consist of a mixture of (a) affective (emotional) reactions to life events or conditions plus (b) cognitive evaluations of those events or conditions against certain comparison criteria. Why 
people have the emotional reactions they do is not yet well understood, and neither is it clear how people's standards of comparison form and change. However, one of the implications of early explorations of the cognitive component is that it seems important to monitor not only people's assessments of well-being, but also their level of aspirations (Andrews \& McKennell, 1980; Mason \& Faulkenberry, 1978; McKennell, 1978; McKennell \& Andrews, 1980).

\section{POTENTIAL AND EXISTING RESEARCH ON POPULATION AND WELL-BEING}

This article has suggested that the developing field of social indicators holds promise for producing new knowledge relevant to population issues. Having now sketched what is meant by social indicators and described some of the key conceptual features of the social indicators area, we can now be somewhat more specific about the research that might begin to fulfill this promise. This section starts by presenting two- and three-dimensional schemas that suggest specific research topics involving population issues and well-being and that also provide a system for classifying previous research in this area. Then the section goes on to briefly review the current state of the knowledge base, citing several clusters of existing studies and observing that there is much further work to be done. This leads to the next section of the paper, where some of the specific problems of carrying out such research are considered.

\section{Linking Aspects of Well-being to Population Phenomena}

If one wishes to investigate the linkage between aspects of well-being and various population phenomena, even the simplest form of research requires a "bivariate" approach-i.e., a variable tapping well-being (selected from the social indicators) will be related to a variable measuring a population characteristic. Knowledge based only on bivariate relationships is not very sophisticated, and one usually must move beyond it to more complex, multivariate models that consider multiple impacts and contingencies. However, even bivariate knowledge is much better than no knowledge, and its relative simplicity suggests it as a starting point. If we take a grand overview of how this new field might develop, we can lay out a two-dimensional schema that arrays 
population measures on one axis and well-being measures on the other. Such a grid is shown in Table 1.

In Table 1, the vertical axis makes reference to some widely discussed population phenomena: ( $1 \mathrm{a}$ ) size of population and ( $1 \mathrm{~b}$ ) changes in population size -i.e., growth, stability, or decline; (2a) the density or crowdedness of population and ( $2 \mathrm{~b}$ ) changes in density or crowding; ${ }^{1}(3 a)$ the age/sex structure of a population and (3b) changes in the age/sex structure; and (4a) the geographic distribution of a population and (4b) changes in geographic distribution (which would include various migration phenomena). All of these topics are basic ones in modern demography. The horizontal axis lists a selection of well-being indicators, all of which have been assessed in existing social indicator studies. The selection proceeds from global indicators to more specific ones and is meant to include both objective and subjective measures. Of course, the listings along the vertical and horizontal axes of Table 1 are intended only as interesting examples and are not intended to comprehend all scientifically or practically important possibilities.

Although the schema in Table 1 is rudimentary, even in this form it begins to suggest many researchable questions. Each cell in the grid directs our attention to policy implications. The upper left cell (cell " $a$ "), for example, focuses on the relationship between population size and overall levels of well-being. Cell " $b$ " includes issues of material welfare as related to the growth, stability, or decline of a population. Cell " $\mathrm{C}$ " addresses the quality of housing as related to housing density and/or perceptions of crowdedness.

The schema in Table 1 can be made considerably more interesting and useful if we elaborate it by adding a third dimension keyed to the type of social unit in which the linkage between population and well-being is being considered. Some discussions of population and well-being are pitched at the most aggregate level of all-the whole world considered as a single unit. ("The earth is becoming overpopulated." "Mankind will not have adequate resources in the future.") At a somewhat lower level, one encounters discussions at the national level. ("Country $X$ needs more people to work in its ...") At still lower levels one finds attention directed to the particular settings in which people live-regions, cities, neighborhoods, et cetera-and to the groups of which people are members-racial, ethnic, class, and many

\footnotetext{
"We follow Stokols (1972) in treating "density" as an objective phenomenon and "crowdedness" as the subjective or perceptual analogue.
} 
FRANK $M$. ANDREWS

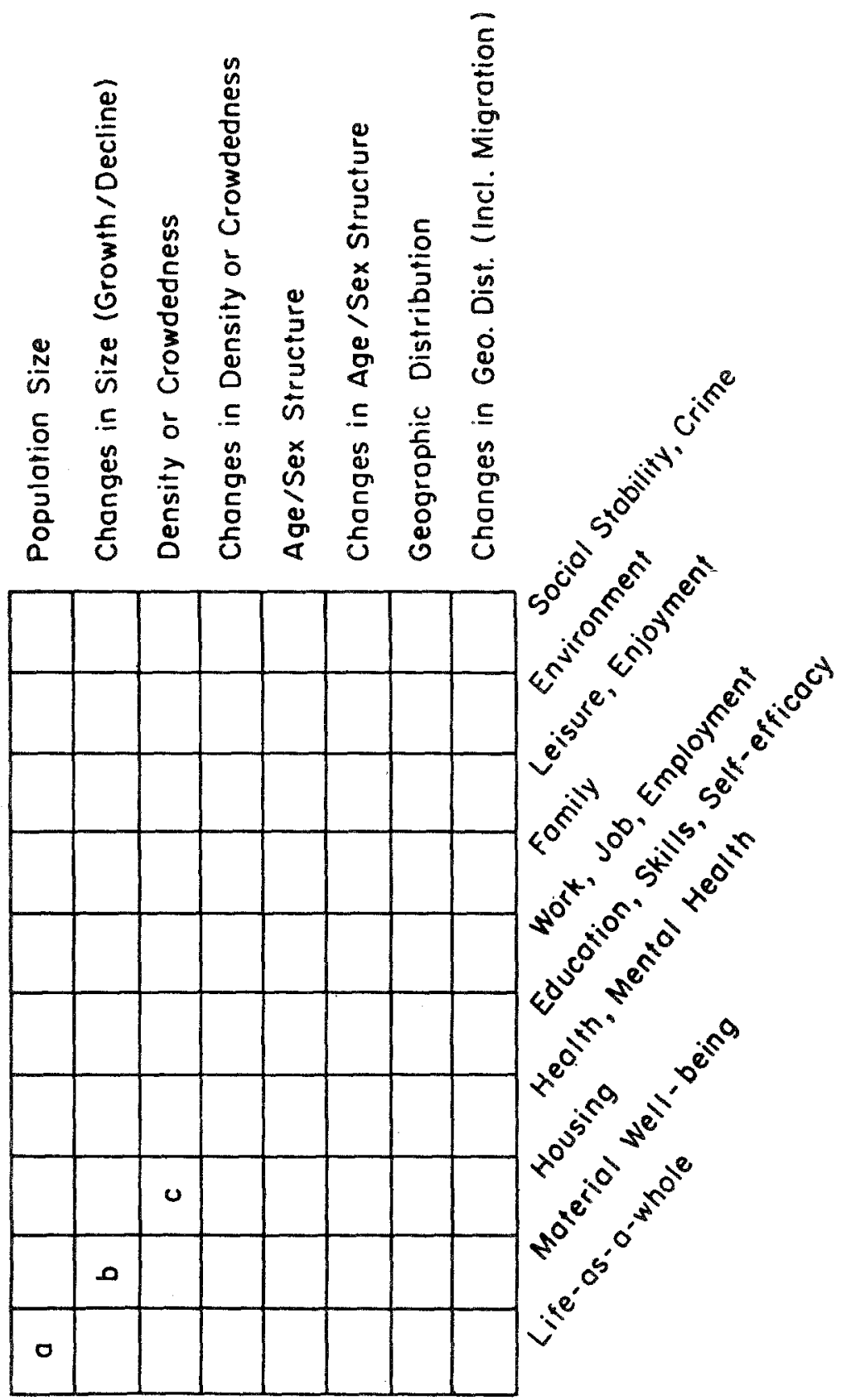


POPULATION AND ENVIRONMENT

more. ("As cities get larger, there tends to be an increase in .. ." "If upper class families tend to have fewer children than lower class families, then ...") Perhaps the smallest social unit that is commonly examined from a population perspective is the family. " As the number of children in a family increases, there is a decrease in...")

As with the first two dimensions of the schema, these categories just suggested for the third dimensions are not exhaustive, but are presented here simply as interesting and commonly examined examples. Table 2 presents the elaborated form of the schema, now depicted as a three-dimensional structure.

This three-dimensional schema is useful for several purposes. It provides (a) a classification scheme for the studies on population and well-being that already exist, (b) a means of checking on where there are "holes" in existing knowledge, and (c) an orderly heuristic for generating potentially interesting questions that can be examined in future research.

The Current State of the Knowledge Base

Although there is great general interest in relationships between population matters and levels of well-being, there are relatively few studies that actually explore these relationships. A scan of the recent social and demographic literature for empirical studies and research-based reports that consider the linkage between population and well-being shows that significant starts have been made in a few areas, but that most cells of Table 2 have received little if any attention. Even the more heavily researched cells rarely include as many as a dozen well-done studies, and it is not uncommon to find conflicting conclusions with respect to the basic relationships. A few examples-chosen for the heterogeneity they indicate - may be of interest.

1. The linkage between population size and environmental/resource constraints has been a significant topic of concern in recent decades. At the worldwide or major world-region levels are the massive and widely cited simulation studies sponsored by the Club of Rome (among others) and conducted by Meadows et al. (1972) and by Mesarovic and Pestel (1974). Results from these and similar studies have led some observers, such as Brown (1978), to focus on the formidable and precipitous decline in well-being that seems linked to continued population growth. However, other observers, e.g., Bahr, Chadwick, \& Thomas (1972) 
FRANK M. ANDREWS

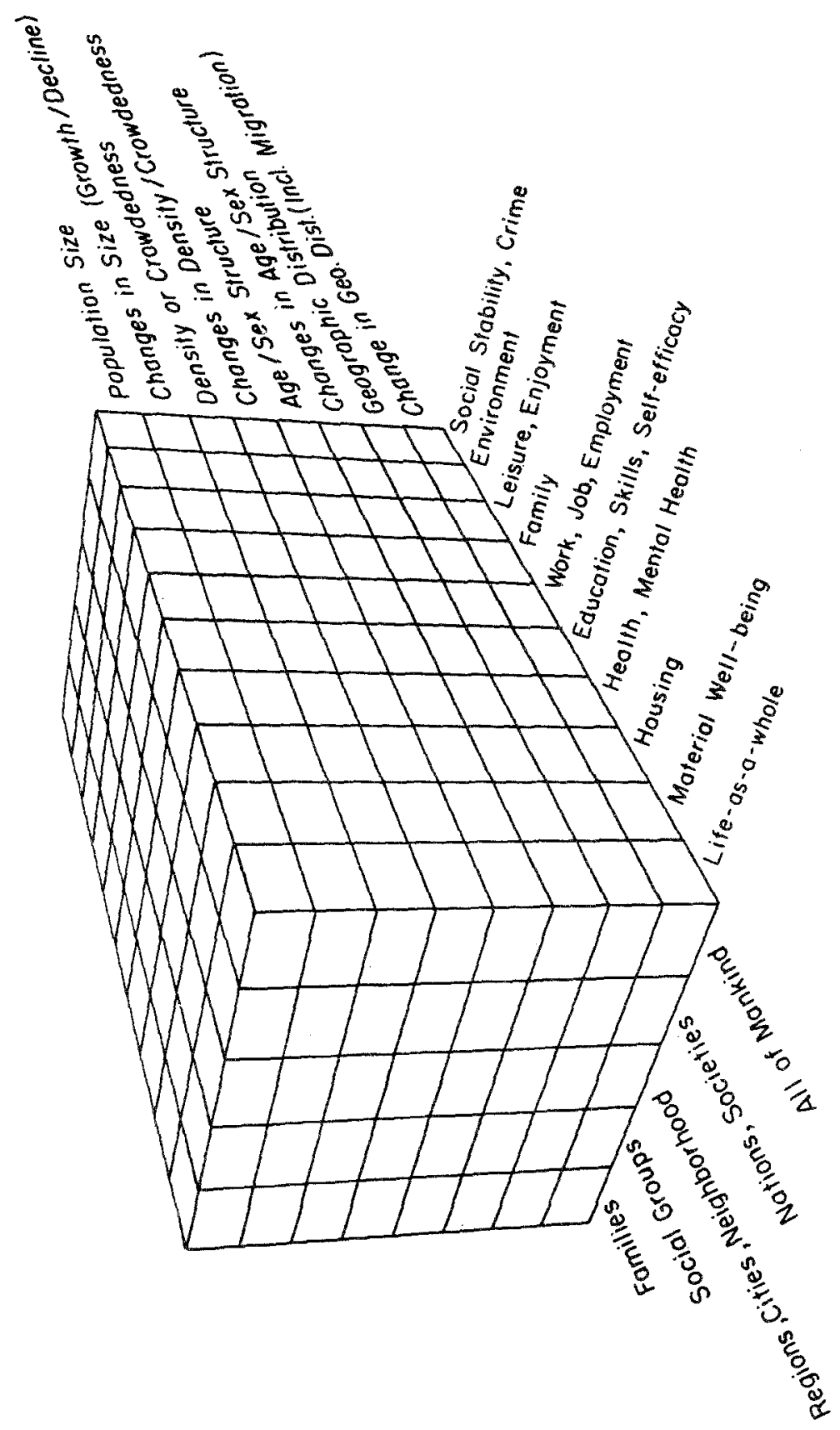


and Simon (1981), have presented opposite points of view. Of course, a full understanding of the linkage between population growth and environmental/resource constraints on well-being will require going beyond the simple bivariate relationships, and while some of the studies mentioned above do that, there still is no consensus about their implications. But this is merely to say that the research done to date has not yet provided the basic knowledge needed to address an issue of great significance.

2. Perhaps one of the most heavily researched cells in our three-dimensional schema is the one at the family level of aggregation where population size (family size, number of children) is related to various measures of well-being, particularly economic well-being. This area is particularly interesting because it includes studies illustrating that the linkage of a population characteristic with a well-being measure need not always have a causal effect assumed to run from population to well-being. Studies by Arnold et al. (1975), Easterlin (1973, 1980), Espenshade (1974), Hoffman (1975), Holm (1975), and Thornton (1978) are among those that explore relationships between family size and well-being. Here the number of relatively good studies lets us begin to develop a sense of what the relationships are and how they vary under different social conditions, and Espenshade (1977) and the U.S. Department of Health, Education, and Welfare (1974) have assembled useful reviews.

3. A third cluster of studies is addressed to the effects of density and crowding on levels of well-being. Although a significant amount of research has been done in this area, as yet there do not seem to be clear conclusions about the conditions under which particular relationships are obtained. For example, studies by Evans (1979), Gove, Hughes \& Galle (1979), and Worchel (1978) all find density and/or crowding associated with enhanced levels of stress, mental illness, and the like, whereas studies by Freedman (1975), Booth and Edwards (1976), and Verbrugge and Taylor (1980) raise doubts about such associations. (See also Baldassare, 1979, 1981; Baum \& Epstein, 1978; and Curkaynak \& Lecompte, 1979.)

4,5 . Two other clusters of studies also merit mention here. One includes studies that link population size or growth to levels of education, and the other includes studies that relate population size and growth to levels of health, nutrition, or mental development. Some of the studies in these clusters assume that the demographic variable is the causal agent (e.g., Jones, 1975; Campbell, 1979; Zajonc, 1976; Zajonc, Markus, \& Markus 1979). 
FRANK M. ANDREWS

However, other studies in these clusters assume the causal direction runs the other way-i.e., the measure of well-being (education, nutrition, et cetera) is presumed to influence the population characteristic (growth, fertility). Works by Caldwell (1980), Glassman and Ross (1978), and Mosley (1978) provide examples.

\section{SOME STRATEGIES FOR INVESTIGATING RELATIONSHIPS BETWEEN POPULATION AND WELL-BEING}

The preceding section of this article noted that research addressing the relationship between population and well-being is still rather sparse, yet suggested that the topic is important and worthy of further investment. The conceptual schema presented in Tables 1 and 2 help to call attention to a wide variety of specific linkages between population and well-being that might merit some (or additional) investigation. The present section of the paper discusses three particular methodological concerns that need to be taken into account when designing research in these areas.

\section{Sources of Variation}

Empirical social science research on phenomena such as the linkage between a characteristic of population and an aspect of well-being proceeds by measuring one or more indicators of each of the phenomena to be related and observing how they covary. In its simplest (bivariate) form, this involves answering questions such as: If $A$ is higher, is $B$ also likely to be higher? If $A$ is higher by one unit, by how much is $B$ likely to be higher? How closely do the B's match the $A^{\prime} s$ ?

Before one can analyze covariation, one must first observe and record it, and there are two basic approaches, either of which could be used for studies of population and well-being, but both of which involve practical problems that must be overcome. One approach is to observe the variation among a set of objects (nations, provinces, towns, families, et cetera) all of which are measured at approximately the same time. The second approach is to observe variation in a single object measured at many different times. The first approach yields what, in survey research, is known as "crosssection" data, while the second approach yields "time series" data. (Of course, one can combine the two approaches and observe variation among a set of objects at several times-a procedure that produces what the survey researchers call "panel" data.) 
These basic methodological matters have strong implications for the design of an empirical study addressed to the linkage between population and well-being. If one takes the cross-section approach, one must have data about both the population parameter and the well-being parameter for the objects one chooses to examine. Census data are often useful for the population information, but finding good well-being data for nations, provinces, towns, et cetera may be difficult. If one takes the time-series approach, one must have both population data and well-being data for many different points in time, and-furthermore-since most population data change only rather slowly, these time points must be spaced well apart (intervals in the range of five to fifty years are probably the right order of magnitude). One of the reasons good time series studies of population and well-being may be slow to develop is because of the long time intervals required, the absence of much good well-being data from the past, and the extensive time it will require to amass enough such data in the future.

\section{A Multilevel Phenomenon}

A second basic methodological matter has to do with the multilevel character of the topic being investigated. Population characteristics are phenomena that refer to an aggregation of people-a whole nation, a city, a family - but not to an individual human being. On the other hand, well-being, as the term bas been used in this paper, refers to the states of individuals. Thus research on population and well-being seems inherently to involve a multilevel approach. Either (a) the well-being of individual members of whatever collectivity is being examined must be aggregated up to the level of the collectivity (examples include per capita gross national product, crime rates, mean levels of satisfaction, et cetera), or (b) the population parameter that characterizes the collectivity must be assigned downward to that collectivity's individual members. It seems likely that the former procedure will most often be used, except perhaps when the collectivities being examined are small, such as families.

While multilevel research does not pose fundamental problems, it is a feature that makes research on the linkage of population and well-being more complex than many others.

If one wanted to avoid approaching the topic as a multilevel one, there are two logical alternatives, though each has the effect of changing the focus of the research somewhat. One alternative is 
to focus entirely on individual-level phenomena. Most of the population characteristics presented in Tables 1 and 2 cannot readily be converted to the level of the individual person, though certain other concepts with relevance to population matters-such as a woman's (or couple's) fertility, preferred family size, and knowledge, attitudes, and practice regarding contraception-can be. Looking at how an individual's well-being covaries as a function of their own individual population-relevant characteristics is a viable and attractive alternative that could be explored more than it has been.

A second alternative is to focus entirely at the collectivity level. The population characteristics presented in Tables 1 and 2 of this paper naturally refer to collectivities and what is required is to develop indicators of well-being that tap how well off a collectivity itself is, and/or how well it is functioning. Such indicators would permit a fascinating and potentially important examination of tradeoffs between individuals' well-being and that of the collectivity. (The "tragedy of the commons" involves just such a tradeoff.) As yet, however, indicators that refer to the well-being of collectivities per se have received much less attention than those that measure the well-being of individuals. ${ }^{2}$ When and if an attractive set of such "macro" well-being indicators became available, this second alternative research design could prove very fruitful.

\section{Contingency Effects}

The conceptual schema in section 4 of this paper started from the simplest approach for examining linkages between population and well-being - the bivariate relationship. While it is useful for exposition and classification, it is insufficient by itself. It would be very surprising if the relationship between a population parameter and an aspect of well-being were always the same. On the contrary, we expect this relationship to vary depending on a wide range of contingent circumstances. Thus productive research on population and well-being will have to be sensitive to the contingencies that influence the relationships obtained. In fact, such research should probably be designed from the start to determine how the simple bivariate relationship varies from one situation to another. Determining what are the factors that produce changes in

${ }^{2}$ Research on organizations-particularly the subdisciplines of organizational behavior and the sociology of organizations - offers leads to such indicators. 
the relationship between a population parameter and an aspect of well-being should be as much a part of the research enterprise as measuring the simple bivariate relationship.

\section{SUMMARY AND CONCLUDING OBSERVATIONS}

The story line of this article runs as follows: New knowledge about the linkage between population and well-being could lead to better decisions about important population issues. Demographers have developed a sophisticated speciality that identifies and measures various characteristics of populations - such as size, growth/decline, density, age/sex structures, location, and migration - but have done little to link these parameters to well-being. In the last fifteen years, the social indicators movement has made significant progress toward a broader and more comprehensive conceptualization of well-being than was available previously and has developed a variety of approaches for measuring well-being at several levels of specificity. Now the opportunity is before us to relate the demographer's measures of population characteristics to the social indicator researchers' well-being measures in order to begin addressing issues having to do with the linkage of population and well-being. Although the potential exists, the needed data may not, and data may have to be amassed before meaningful analysis can be carried out.

A conceptual schema is presented for suggesting the spcific relationships that might be examined and the various levels of social aggregation to which they might be tied. This conceptual schema helps to classify - i.e., assemble into topical clusters - the relatively modest amount of research that has already been done linking population and well-being (examples of which are given) and helps to identify other areas that have received little or no attention.

Although the potential for productive research in this area seems great, there are some special methodological features-the inherent multilevel nature of the relationships being investigated (involving properties of individuals and of collectivities), the slow rate at which population characteristics change, the absence of much good well-being data, and the limited nature of the collectivities for which population data are available - that suggest that considerable time and care may be required to produce dependable new knowledge about the linkage between population parameters and well-being. 
FRANK M. ANDREWS

\section{REFERENCES}

Andrews, F. M. Social indicators of perceived life quality. Social Indicators Research, 1974, 1, 279-299.

Andrews, F.M. Subjective social indicators, objective social indicators, and social accounting systems. In: Juster, F.T. and Land, K. C. (eds.), Social accounting systems: Essays on the state of the art. Academic Press, New York, 1981.

Andrews, F. M. and McKennell, A. C. Measures of self-reported well-being: Their affective, cognitive, and other components. Social Indicators Research, 1980, 8, 127-155.

Andrews, F. M., and Withey, S. B. Developing measures of perceived life quality: Results from several national surveys. Social Indicators Research, 1974, 1, 1-26.

Andrews, F. M. and Withey, S.B. Social indicators of well-being: Americans' perceptions of life quality. New York: Plenum, 1976.

Arnold, $F$. et al. The value of children: A cross-national study. Honolulu: East-West Population Institute, 1975.

Atkinson, T., Blishen, B., and Murray, M. Physical status and perceived health quality. Working papers on the quality of life in Canada. Downsview, Ontario: York University, Institute for Behavioural Research, 1980.

Bahr, H.M., Chadwick, B.A., and Thomas, D. (eds.). Population, resources, and the future: Non-Malthusian perspectives. Provo, Ut.: Brigham Young University Press, 1972.

Baldassare, M. Residential crowding in urban America. Berkeley, Ca.: University of California Press, 1979.

Baldassare, $M$. The effects of household density on subgroups. American Sociological Review, 1981, 46, 110-118.

Baum, A. and Epstein, Y. M. (eds.). Human response to crowding. Hillsdale, N.J.: Erlbaum, 1978.

Booth, A. and Edwards, J. N. Crowding and family relations. American Sociological Review, $1976,41,308-321$

Brown, L.R. The 29th day: Accommodating human needs and numbers to earth's resources. New York: Worldwatch Institute, 1978.

Caldwell, J.C. Mass education as a determinant of the timing of fertility decline. Population and development review, 1980, 6, 225-256.

Campbell, A.A. (ed.). Social, economic, and health aspects of low fertility, Washington, D.C: U.S. Government Printing Office, 1979.

Campbell, A., Converse, P.E., and Rodgers, W.L. The quality of American life: Perceptions, evaluations, and satisfactions. New York: Russell Sage Foundation, 1976.

Easterlin, R. A. Relative economic status and the American fertility swing. In: Sheldon, E. B. (ed.), Social structure, family life styles, and economic behavior. Philadelphia: Lippincott, 1973.

Easterlin, R. A. Birth and fortune. New York: Basic Books, 1980.

Espenshade, T.J. Estimating the costs of children and some results from urban United States. Social Indicators Research, 1974, 1(3), 359-381.

Espenshade, T. J. The value and cost of children. Population bulletin, 1977, 32(1), 1-47.

Evans, C.W. Behavioral and psychological consequences of crowding in humans. Journal of applied social psychology, 1979, 9(1), 27-46.

Freedman, J. Crowding and behavior: The psychology of high density living. San Francisco: Freeman, 1975.

Gilmartin, K. J., Rossi, R. J., Lutomski, L. S., and Reed, D. F. B. Social indicators: An annotated bibliography of current literature. New York: Garland, 1979.

Glassman, M. B., and Ross, J. A. Two determinants of fertility decline: A test of competing models. Studies in family planning, 1978, 9(7), 193-197.

Gove, W. R., Hughes, M., and Galle, O.R. Overcrowding in the home: An empirical investigation of its possible pathological consequences. American Sociological Review, $1979,44,59-80$.

Gurkaynak. M. R., and Lecompte, W. A (eds.) Human consequences of crowding. New York: Plenum, 1979. 
Hoffman, L.W. The value of children to parents and the decrease in family size. Proceedings of the American Philosophical Society, 1975, 119, 430-438.

Hofstede G. Motivation, leadership, and organization: Do American theories apply abroad? Organizational dynamics, 1980 (Summer), 42-63.

Holm, C. F. Social security and fertility: An international perspective. Demography, 1975 , 12(4), 629-644. (Response: Kelly, W. R. et al. Demography, 1976, 13(4), 581-586. Reply: Holm, C. F. Demography, 1976, 13(4), 587-589.)

Jones, G. Population growth and educational planning in developing nations. New York: Irvington, 1975.

Land, K. C. On the definition of social indicators. American sociologist, 1971, 6, 322-325.

Liu, B. C. The quality of life in the United States, 1970. Kansas City, Mo.; Midwest Research Institute, 1970.

Liu, B.C. Quality of life in U.S. metropolitan areas, 1970. Washington, D.C.: U.S. Environmental Protection Agency, 1975.

Mason, R., and Faulkenberry, G. D. Aspirations, achievements, and life satisfactions. Social indicators research, 1978, 5,133-150.

McKennell, A. C. Cognition and affect in perceptions of well-being. Social indicators research, 1978, 5, 389-426.

McKennell, A. C., and Andrews, F. M. Models of cognition and affect in perceptions of wellbeing. Social indicators research, 1980, 8, 257-298.

Meadows, D. H. et al. The limits to growth. New York: Universe Books, 1972.

Mesarovic, M. and Pestel, E. Mankind at the turning point. New York: Dutton, 1974.

Mosley, W. H. (ed.). Nutrition and human reproduction. New York: Plenum, 1978.

Organization for Economic Cooperation and Development (OECD). Measuring social wellbeing. Paris: OECD, 1976.

Sawhill, I. V. The role of social indicators and social reporting in public expenditure decisions. In: The analysis and evaluation of public expenditures: The PBB system, Volume I. Washington, D.C.: U.S. Government Printing Office, 1969

Sheldon, E. B., and Freeman, H. E. Notes on social indicators: Promises and potential. Policy sciences, 1970, 1, 97-111

Simon, J. L. The ultimate resource. Princeton, N.J.: Princeton University Press, 1981.

Stokols, D. On the distinction between density and crowding: Some implications for further research. Psychological Review, 1972, 79, 275-277.

Tabah, L. World population trends: A stocktaking. Population and development review, $1980,6,355-389$.

Thornton, A. Relationship between fertility and income, relative income, and subjective well-being. In: Simon, J. L. (ed.), Research in population economics, Volume I, 1978.

United States Department of Health, Education and Welfare. Toward a social report. Washington, D. C.: U. S. Government Printing Office, 1969.

United States Department of Health, Education and Welfare (National Institute of Child Health and Human Development, Center for Population Research). A review of actual and expected consequences of family size. Washington, D.C.: U. S. Government Printing Office (Publication \#76-779), 1974.

Verbrugge, L. M. and Taylor, R. B. Consequences of population density and size. Urban Affairs Quarterly, 1980, 16, 135-160.

Wasserman, I. M., and Chua, L. A. Objective and subjective social indicators of the quality of life in American SMSA's: A reeanalysis. Social Indicators Research, 1980, 8, 365-381.

Worchel, S. Reducing crowding without increasing space: Some applications of an attributional theory of crowding. Journal of population, 1978, 1(3), 216-230.

Zajonc, R. B. Family configuration and intelligence. Science, 1976, 192, 227-236.

Zajonc, R. B., Markus, H., and Markus, G. B. The birth order puzzle. Journal of personality and social psychology, 1979, 37(8), 1325-1341. 